\title{
Opening Doors for Learners: Barriers and Challenges at the Open University of Sri Lanka
}

\author{
C M Hill* \\ Consultant, OUSL-CE Project, Simon Fraser University
}

Research was conducted in order to identify psychological, personal, and institutional barriers that may hinder academic achievement and lead to non-completion at the Open University of Sri Lanka (OUSL). Methods included exploratory interviews with 67 learners and staff, and the development and implementation of the Learner Support Questionnaire, which was administered to 227 learners. Findings indicate that many OUSL learners have an inadequate understanding of Open and Distance Learning, a limited repertoire of study strategies, insufficient metacognitive skills, and are overly dependent on teacher-centred pedagogies. Learners, particularly less experienced learners, may overestimate their academic abilities. Other barriers to success including personal and institutional factors are discussed.

\section{Introduction}

The purpose of this study was to learn more about the psychological, personal, and institutional factors that may hinder learners' ability to fulfill their academic goals at the Open University of Sri Lanka (OUSL). There is justification for investing in learner support including pragmatic justification, such as recruitment, retention, and learner satisfaction, as well as theoretical, and moral justification (Simpson, 2002). Understanding the needs of learners at this particular institution, at this particular time, is very important as the student population at the OUSL is currently in a state of flux.

As a result of government mandates, the OUSL is expected to double its enrollment by 2009. With changes in the enrollment at the OUSL, the student population may increasingly consist of a younger group of learners with less occupational and life experiences, who may have more difficultly adjusting to post-secondary education, as well as to Open and Distance Learning (ODL) methods. Therefore, it is vital to ensure that the needs of learners at the OUSL are understood and that the appropriate support structures are in place as the university population increases. 
The primary goal of this study was to learn more about learners' abilities, beliefs and perceptions, particularly in regard to their academic skills, as study skills have been found to be related to academic performance in both Eastern (Yip \& Chung, 2005) and Western (Ross et al, 2003) post-secondary institutions. A secondary goal of this study was to identify other factors that may enable or constrain student achievement in order to reduce barriers and capitalize on existing support structures.

\section{Method}

The research design involved a two phased approach, including exploratory interviews with staff and learners, and the development of a questionnaire which was distributed to the student population. Wherever possible, data was triangulated with information from other sources.

\section{Interviews}

Interview questions were formulated on the basis of educational theory including self-regulated learning (Puustinen \& Pulkkinen, 2001), and learners' approaches to learning (Biggs, Kember \& Leung, 2001), as well as prior research conducted at the OUSL (Gamaathige \& Dissanayake, 1999; Jayatilleke, 1997; Raheem \& Ratwatte, 1997). The interviews, which were semi-structured, addressed issues related to barriers and supports for learners, challenges associated with ODL, required academic skills, learners' scholarly abilities, reasons for attrition, and the suitability of entry requirements.

Interviews were conducted individually or in groups (focus group discussions) based on the preference of the participants and time constraints. Nineteen interviews were conducted with 67 people including 43 learners, 15 academic staff, 5 Department Heads, 3 Deans, and 1 Assistant Librarian. Efforts were made to ensure that academic staff and learners from all faculties were represented. The interviews were conducted in English or Sinhala.

\section{Questionnaire}

The development of the Learner Support Questionnaire (LSQ) was formulated using interview data, relevant educational theory, including knowledge building theory (Bereiter \& Scardamalia, 1996) and Bloom's taxonomy (1956), as well as prior research conducted at the OUSL 
(Calder \& Wijeratne, 1999; Dassanayake, de Zoysa, \& Jayatilake, 1999; Jayatilleke, 2002; Jayatilleke, 2005).

The LSQ is a self-report measure that includes open-ended questions, yes or no questions, as well as rating scales. The questionnaire assessed learners' perceptions of their academic ability, their understanding of ODL, their study practices, and the challenges that may hinder academic achievement. The LSQ was pilot tested, revised, and translated into Sinhala and Tamil. In order to differentiate between learners' perceptions and their actual practices, multiple questions targeting similar information were included to assess the validity of participants' responses. For example, participants were asked if they set learning goals, to rate their ability to set such goals, and then to provide examples of their learning goals.

The LSQ was distributed to twelve classes at the Colombo Regional Centre from the certificate level to the postgraduate level, within nine different departments and across all four faculties (Table 1). 227 learners completed the questionnaire.

Table 1: Distribution of Questionnaire by Faculty and Level

\begin{tabular}{|l|l|l|c|}
\hline Faculty & Classes & Number of Classes & $\begin{array}{l}\text { Number of } \\
\text { Participants }\end{array}$ \\
\hline \multirow{2}{*}{ Education } & Certificate & 1 & 24 \\
\cline { 2 - 4 } & Masters & 1 & 16 \\
\hline \multirow{2}{*}{$\begin{array}{l}\text { Sumanities and } \\
\text { Social Sciences }\end{array}$} & Level 3 & 1 & 03 \\
\cline { 2 - 4 } Technology & Level 6 & 1 & 17 \\
\hline \multirow{2}{*}{ Natural Sciences } & Foundation & 1 & 09 \\
\cline { 2 - 4 } & Level 4 & 1 & 12 \\
\cline { 2 - 4 } & Level 5 & 1 & 05 \\
\cline { 2 - 4 } & Level 3 & 3 & 41 \\
\cline { 2 - 4 } & Level 5 5 & 1 & 18 \\
\hline Total & & 12 & 227 \\
\hline
\end{tabular}

$65 \%$ of the participants were female and 35\% were male. Learners' ages ranged from 20 to 72 and the majority of learners (54\%) were 25 or younger. Of those who disclosed their ethnicity, 94\% were Sinhalese, $4 \%$ were Tamil, 1\% was Malay, and 1\% was Sri Lankan Moor. Learners' family incomes ranged from under 4,999 Rupees per month to over 50,000 Rupees per month; however the majority of learners $(74 \%)$ reported an income of less than 20,000 Rupees a month. $27 \%$ of the participants were married and, of those who reported their familial status, $27 \%$ were parents. $42 \%$ of the learners were employed full- 
time; $16 \%$ part-time, $38 \%$ were not employed, and $4 \%$ reported an alterative employment status.

$60 \%$ of learners considered themselves part-time, and $40 \%$ considered themselves full-time learners. 57\% of learners were studying in the English medium, 40\% in the Sinhala medium, and 3\% in the Tamil medium. The majority of learners (84\%) were attached to the Colombo Regional Centre, however $16 \%$ of participants were affiliated to other regional or study centres. Although the sample is not representative of the entire OUSL student population, it does reflect a diverse group of learners. The main limitations in this sample are its lack of ethnic and geographical diversities.

\section{Results and Discussion}

The results section is comprised of three subsections:

1. Psychological factors,

2. Personal factors, and

3. Institutional factors that may limit a learner's ability to succeed.

Many of these concerns are interrelated and may lead to compound problems for learners.

\section{Psychological Factors}

Perceptions of Ability and Importance of Skills

Learners were asked to rate their ability with regard to 26 skills associated with learning, as well as to rate the importance of these skills for achieving success in their study programmes. The majority of learners rated their abilities very positively and were of the view that most of the skills listed were essential to their success (Table 2). 
Table 2: Mean Ratings of Ability and Importance of Skills

\begin{tabular}{|l|l|l|l|l|}
\hline & $\begin{array}{l}\text { Mean } \\
\text { Ability }\end{array}$ & $\begin{array}{l}\text { Mean } \\
\text { Importance }\end{array}$ & $\begin{array}{l}\text { Ability } \\
\text { - Rank }\end{array}$ & $\begin{array}{l}\text { Importance - } \\
\text { Rank }\end{array}$ \\
\hline Preparing for continuous assessment & 1.583 & 1.252 & 1 & 04 \\
\hline Persisting in achieving academic goals & 1.609 & N/A & 2 & N/A \\
\hline Setting goals to guide your learning & 1.611 & 1.266 & 3 & 05 \\
\hline Preparing for exams & 1.618 & 1.251 & 4 & 03 \\
\hline Identifying what you don't know & 1.652 & 1.333 & 5 & 06 \\
\hline Ability to work independently & 1.671 & 1.493 & 6 & 13 \\
\hline Being able to identify important ideas & 1.676 & 1.392 & 7 & 09 \\
\hline Planning and organizing study time & 1.686 & 1.109 & 8 & 01 \\
\hline $\begin{array}{l}\text { Understanding concepts, facts and } \\
\text { theories }\end{array}$ & 1.713 & 1.402 & 9 & 10 \\
\hline English language skills & 1.738 & 1.176 & 10 & 02 \\
\hline Ability to seek support when needed & 1.772 & $\mathrm{~N} / \mathrm{A}$ & 11 & $\mathrm{~N} / \mathrm{A}$ \\
\hline Ability apply knowledge & 1.780 & 1.362 & 12 & 07 \\
\hline Problem solving skills & 1.783 & 1.378 & 13 & 08 \\
\hline Ability evaluate ideas & 1.816 & 1.634 & 14 & 20 \\
\hline Ability to revise, edit or improve work & 1.833 & 1.473 & 15 & 12 \\
\hline Ability generate new ideas & 1.886 & 1.547 & 16 & 16 \\
\hline $\begin{array}{l}\text { Remembering concepts, facts, and } \\
\text { theories }\end{array}$ & 1.894 & 1.500 & 17 & 15 \\
\hline Analytical skills & 1.899 & 1.618 & 18 & 19 \\
\hline Managing stress/anxiety & 1.910 & $\mathrm{~N} / \mathrm{A}$ & 19 & $\mathrm{~N} / \mathrm{A}$ \\
\hline Ability to synthesize ideas & 1.917 & 1.577 & 20 & 17 \\
\hline Library skills & 1.941 & 1.578 & 21 & 18 \\
\hline Ability to ask good questions & 1.966 & 1.646 & 22 & 21 \\
\hline $\begin{array}{l}\text { Breakdown projects into manageable } \\
\text { tasks }\end{array}$ & 1.995 & 1.721 & 23 & 23 \\
\hline Ability to seek feedback on your work & 2.064 & 1.472 & 24 & 11 \\
\hline Research skills & 2.185 & 1.821 & 25 & 25 \\
\hline Writing academic papers & 2.443 & 2.186 & 26 & 26 \\
\hline Contact with teachers & $\mathrm{N} / \mathrm{A}$ & 1.498 & $\mathrm{~N} / \mathrm{A}$ & 14 \\
\hline Group work & $\mathrm{N} / \mathrm{A}$ & 1.662 & $\mathrm{~N} / \mathrm{A}$ & 22 \\
\hline Contact with Fellow learners & 1.775 & $\mathrm{~N} / \mathrm{A}$ & 24 \\
\hline N & $\mathrm{A}$ & $\mathrm{A}$ & \\
\hline
\end{tabular}

$1=$ excellent/very important; $2=$ good/ important, $3=$ limited/somewhat important, $4=$ poor $/$ not important 
Learners indicated that the preparation for continuous assessments and examinations, the setting of academic goals, persisting in achieving these goals, and identifying what they do not know as their five strongest skills. All of these skills (excluding persistence, which was not rated in terms of importance) were also ranked among the most important skills for achieving academic success. Overall, learners identified assessment related and motivational skills, rather than cognitive skills, as their primary academic assets.

Learners ranked organizing study time, as well as a knowledge of English language among the most important skills, which is not surprising as many programmes at the OUSL are offered in English. Although English skills were ranked tenth in terms of ability, over $80 \%$ of learners rated their English as good or excellent; and only three learners specifically identified a lack of language skills as an obstacle to their academic performance (Table 3). Teachers in all the faculties however reported that an inadequate knowledge of English was a drawback to their success. Other studies conducted at this University have also identified the lack of English language skills as an impediment to programme completion (Gamaathige \& Dissanayake, 1999).

Table 3: Difficulties identified by learners in the questionnaire

\begin{tabular}{|l|l|}
\hline Barrier & Frequency \\
\hline Work related challenges & $48(15 \%)$ \\
\hline Cost excessive/financial problems & $34(10 \%)$ \\
\hline Strikes & $31(10 \%)$ \\
\hline Commute problematic & $22(7 \%)$ \\
\hline Lack of time/programme too time consuming & $22(7 \%)$ \\
\hline Not enough contact learning & $19(6 \%)$ \\
\hline Regional/study centre inadequate & $17(5 \%)$ \\
\hline Inadequate resources & $16(5 \%)$ \\
\hline Inadequate facilities & $14(4 \%)$ \\
\hline Lack of interaction with teachers & $14(4 \%)$ \\
\hline Difficulties associated with independent study & $14(4 \%)$ \\
\hline Inadequate course material & $13(4 \%)$ \\
\hline Restrictive Policy & $13(4 \%)$ \\
\hline Quality of instruction & $12(4 \%)$ \\
\hline Family issues & $10(3 \%)$ \\
\hline Unanticipated changes/scheduling problems & $8(2 \%)$ \\
\hline Lack of communication with the institution & $5(2 \%)$ \\
\hline Language barriers & $3(1 \%)$ \\
\hline Age & $1(.3 \%)$ \\
\hline
\end{tabular}


Learners rated writing papers, research skills, seeking feedback, breaking down large projects into manageable tasks, and the ability to ask appropriate questions as their five weakest skills. Writing papers, conducting research, and working on large projects are often most important in the final years of a bachelor degree or a postgraduate degree, and consequently these skills may be less familiar to many learners in the sample. Indeed these skills were ranked lowest with importance. Learners may have rated their ability to seek feedback as lower in comparison to other abilities, despite ranking it higher in terms of importance, because they had difficulty contacting teachers. The ability to ask appropriate questions requires more abstraction than that required by some of the other skills and consequently may be an indispensable skill for university learners to acquire.

\section{Strategy Use}

$75 \%$ of learners reported using mnemonic strategies to help them remember course material however, only $60 \%$ of learners reported using such strategies to help them understand course material. Of those learners who described their learning strategies, few listed more than one strategy for remembering $(41 \%)$ or for understanding $(29 \%)$, which may indicate that OUSL learners have a limited repertoire of such learning strategies.

The most common strategies listed for remembering were short notes (70\%), visual representations (10\%), peer discussions $(8 \%)$, reorganizing material $(8 \%)$, and reading or re-reading texts $(8 \%)$. The most common strategies listed for understanding were reading external resources $(31 \%)$, discussion with peers $(22 \%)$, reading or re-reading texts $(11 \%)$, asking the teacher $(10 \%)$ and short notes $(9 \%)$. Many of these strategies, including those strategies mentioned above are potentially useful and effective strategies only if the learners are actively engaged in processing information and constructing knowledge. Unfortunately, most learners did not elaborate on how they used these strategies. Simply reading or re-reading the text is a passive strategy and not a very efficient one for remembering and understanding course material. Asking the teacher questions can enhance learners' understanding; however it is a teacher-centred strategy and is not as practical as a primary learning strategy for ODL learners. 


\section{Motivational Skills}

$90 \%$ of learners stated that they set goals for themselves as learners and $91 \%$ rated their ability to set these goals as "excellent" or "good". The majority of learning goals described however, were general and/or long term, and were performance related (aimed at enhancing the appearance of competency) or externally motivated (Table 4). Few learners listed mastery goals, which involves learning a set of skills or mastering a body of knowledge, or goals that were specific and short term. Learning goals that are the most effective are goals that are specific, short-term, moderately difficult, set by the learner, and mastery related (Schunk, 2002).

Table 4: Goals set by Learners

\begin{tabular}{|l|l|l|}
\hline & Specific and Short Term & $\begin{array}{l}\text { General and/or Long } \\
\text { term }\end{array}$ \\
\hline Performance/External & $2 \%$ & $66 \%$ \\
\hline Example & $\begin{array}{l}\text { "get a high distinction in this } \\
\text { course" }\end{array}$ & $\begin{array}{l}\text { "finish the degree as } \\
\text { soon as possible" }\end{array}$ \\
\hline Mastery/Internal & $0 \%$ & $12 \%$ \\
\hline Example & $\begin{array}{l}\text { "to understand the learning } \\
\text { objectives for each unit" }\end{array}$ & $\begin{array}{l}\text { "become a learned } \\
\text { man" }\end{array}$ \\
\hline Organizational/Motivational & $9 \%$ & $14 \%$ \\
\hline Example & $\begin{array}{l}\text { "I prepare a time table...and } \\
\text { follow it" }\end{array}$ & $\begin{array}{l}\text { "never never never give } \\
\text { up" }\end{array}$ \\
\hline
\end{tabular}

\section{Metacognitive Skills}

$88 \%$ of learners rated their ability to identify what they do not know and need to understand as "good" or "excellent". 56\% of those who described how they assessed their learning of course material, based their evaluation on their ability to complete exams, assignments, and past questions; $40 \%$ on marks or feedback from teachers, $12 \%$ through explanation or discussion; $12 \%$ using personal self-assessment techniques; $4 \%$ through self-assessment questions or learning objectives, $4 \%$ through reading; and $2 \%$ by the confidence they have in their knowledge. Several learners (1\%) noted that they do not have time to evaluate their own learning. Although most learners rated their selfassessment skills favourably, they were largely dependent on external feedback to gauge their understanding. Few learners reported using personal or course related self-assessment techniques. 
Opening Doors for Learners

Independent Learning Skills

$87 \%$ of learners rated their ability to work independently as "excellent" or "good" and only 14\% of learners specifically identified challenges associated with ODL as a barrier to their academic success. Many teachers however, reported that learners' dependence on didactic, teacher-centred pedagogies and the lack of independent learning skills were major challenges for OUSL learners. As one faculty member explained,

Learners are used to tuition classes, which are exam oriented classes. Since this is a distance education mode, we give them all the material and one contact session per month. They expect us to teach the way the tuition classes and school teachers teach. Day school is there to discuss their problems. They expect lecture type classes. They prefer spoonfeeding kind of teaching. That's why they find it difficult to fit into the system.

\section{Understandings of $O D L$}

95\% of learners agreed that day schools differed from classes at conventional universities. Of those who provided reasons, 54\% stated that less material was presented at day schools, $26 \%$ said that there was less instruction or less contact with teachers at day schools, $15 \%$ stated that day schools were to augment self-study, 5\% reported that quality teaching was lacking, $2 \%$ said that day schools were optional, $1 \%$ said that day schools were not on a fixed schedule, $1 \%$ stated that there were less facilities at day schools, and 1\% said that there were more assignments at day schools, compared to conventional university classes. While learners recognized that ODL institutions differ from traditional universities, in many cases this understanding was limited to superficial features and very few learners acknowledged that the purpose or pedagogy of day schools differ from that of traditional university classes.

Learners were asked how they should prepare for day schools and how they actually prepared for day schools. $84 \%$ of learners reported that they read the course material, $21 \%$ said that they prepared questions to ask the teacher, $8 \%$ reported that they review questions, assignments or past question papers, $8 \%$ said that they do nothing or have no time to prepare, $6 \%$ said that they answer the self-assessment questions, $1 \%$ said that they revised their work on that day itself, $1 \%$ reported that they review work from previous day schools, $1 \%$ said that they search the internet, and an additional 1\% said that they submit 
their questions before the classes commence. Most learners thought that reading the course material was sufficient preparation. There was little difference between how learners thought they should prepare and how they actually did prepare for day schools, which indicates that learners' minimal preparation for day schools by learners may reflect a lack of understanding of ODL objectives rather than a lack of effort.

An ANOVA followed by a Turkey post hoc analysis revealed that entrylevel learners (certificate, foundation, and level 3) and intermediate (level 4) rated themselves higher on most of the 26 academic skills than advanced learners (levels 5, 6, and postgraduate) ( $\mathrm{p}<.05)$. Entry-level learners rated themselves higher than advanced learners on all 26 skills except for the ability to ask appropriate questions, to work independently, and to write academic papers. Intermediate learners rated themselves higher than advanced learners on all skills except for the ability to evaluate ideas, to identify what they did not know, and to write academic papers. There was no difference between entry-level and intermediate learners. These results were unexpected but were consistent with a study conducted by Kruger and Dunning (1999) who found that less competent people overestimated their own level of skills to a greater extent than more knowledgeable people.

There were very few differences in rating of the importance of the 26 skills between novice, intermediate, and advanced learners. An ANOVA followed by a Turkey post hoc analysis $(p<.05)$ revealed that entry-level learners rated identifying what they did not know, English language skills, and research skills as more important than advanced learners. Intermediate learners rated identifying what they did not know, English language skills, and the ability to synthesize ideas as more important than advanced learners. Advanced learners rated writing academic papers as more important than entry level or intermediate learners.

Two distinct types of learners were identified in the sample: those who consider themselves full-time (FT) and those who consider themselves part-time (PT) learners. The majority of PT learners $(63 \%)$ were employed full-time and the majority of FT learners $(76 \%)$ were not employed. PT learners were more likely to be married $(x 2=26.82$, $\mathrm{p}<.05)$, and have children $(\mathrm{x} 2=20.28, \mathrm{p}<.05)$, than FT learners. PT learners reported a higher monthly household income $(x 2=14.26,<.05)$ and were older than FT learners $(\mathrm{F}=35.03, \mathrm{p}<.05)$. The average age of PT learners was 31 and the average age of FT learners was 24. Men and women were equally represented among FT and PT learners. 
FT learners reported spending more time on their studies than PT learners $(\mathrm{F}=6.5, \mathrm{p}<.05)$. On average, $\mathrm{FT}$ learners reported spending 33 hours per week on their studies; whereas PT learners reported spending an average of 19 hours per week, despite the fact that there was no difference between the learners' current course credits, or the time that they believed that they should spend on their studies (32 hours per week). PT learners reported that they would be less likely to enroll in a non-mandatory $(\mathrm{x} 2=6.41, \mathrm{p}<.05)$ or a non-credit $(\mathrm{x} 2=8.5$, $\mathrm{p}<.05)$ study skills course than FT learners. PT and FT learners were equally likely to report setting learning goals and using strategies to aid in their understanding; however PT learners were less likely to report using strategies to help them remember course material than FT learners $(\mathrm{x} 2=4.74, \mathrm{p}<.05)$. Perhaps PT learners were less concerned with memorizing texts than FT learners, as they considered the ability to remember as less important than FT learners.

An ANOVA $(\mathrm{p}<.05)$ revealed that PT learners rated their ability lower on sixteen of the 26 academic skills than FT learners. No differences were found between PT and FT learners' self-reports of ability in the application of knowledge, generating new ideas, identifying what is not known, asking appropriate questions, breaking down large projects into manageable tasks, writing papers, working independently, problem solving, and the ability to revise their work. Perhaps FT learners are more confident with regard to many academic skills because they have more time to dedicate to their studies. Alternatively PT learner may be less likely to be confident with regard to their abilities as a result of their work related experience. There were few differences between FT and PT learners with regard to their perceptions of the importance of the skills. PT learners rated setting learning goals $(\mathrm{F}=4.72, \mathrm{p}<.05)$ and synthesizing information $(\mathrm{F}=6.93, \mathrm{p}<.05)$ as more important than FT learners. FT learners rated remembering concepts $(\mathrm{F}=5.08, \mathrm{p}<.05)$, preparing for exams $(\mathrm{F}=6.09, \mathrm{p}<.05)$, English skills $(\mathrm{F}=5.502, \mathrm{p}<.05)$, research skills $(\mathrm{F}=5.26, \mathrm{p}<.05)$, and preparing for assessment $(\mathrm{F}=5.29, \mathrm{p}<.05)$ as more important than PT learners.

Very few differences were found between male and female learners. Female learners rated their ability to write academic papers $(F=5.24$ $\mathrm{p}<.05)$ and to work independently $(\mathrm{F}=4.7, \mathrm{p}<.05)$ higher than male learners. Female learners placed a higher value on some metacognitive skills including the ability to identify important ideas $(F=7.2, \mathrm{p}<.05)$ and the ability to identify what is not known $(\mathrm{F}=5.4, \mathrm{p}<.05)$, as well as having contact with learners $(\mathrm{F}=9.28, \mathrm{p}<.05)$ and teachers $(\mathrm{F}=4.42$, $\mathrm{p}<.05)$ than male learners. Male learners were more likely to report that they would enroll in a non-mandatory $(\mathrm{x} 2=4.09, \mathrm{p}<.05)$ or a non- 
credit $(\mathrm{x} 2=5.18, \mathrm{p}<.05)$ study skills course than female learners. No gender-related differences were found with regard to self-reports of time that was or should be spent on studies, goal setting, or the use of strategies for remembering or understanding course material. Due to the limited representation of different levels of learners within each faculty, no analyses comparing dependent measures by faculty were conducted.

\section{Personal Factors}

\section{Work Related Challenges}

One of the most common challenges reported by OUSL learners was balancing their roles as employees and as learners (see Table 3).

Learners who work may have difficulty completing course work and may be unable to attend practicals and examinations. For example, one student stated,

"as most exam and practical fall in weekday, there is difficulty in getting leave from a private work."

Providing opportunities for learners to complete mandatory face to face components on evenings or weekends may enable more learners to complete their course work.

\section{Financial Difficulties}

Many learners reported concerns regarding the cost of tuition and personal financial difficulties that interfered with their ability to succeed in their programmes. Financial problems may inadvertently create other challenges for learners. For example, one student reported,

"financial difficulties exist. Because of the need to work, that adds additional responsibilities."

\section{Commuting}

Some learners commute to Colombo when programmes are not offered or resources are inadequate at their regional or study centres. Traveling to the Colombo campus can be expensive and time consuming for learners. 


\section{Time Related Concerns}

Learners also reported that the lack of time, or the extent of the time commitment required for their programme interfered with their ability to successfully complete their studies. Programmes that are long or drawn out for various reasons may lead to attrition. Some employed learners voiced concerns with regard to competing with an increasing number of unemployed learners who were able to work on their studies full time.

\section{Familial Responsibilities}

Some learners experienced difficulty balancing their commitments to their studies and to their families. For example, one student reported that she experienced,

"difficulties writing the assignments with the children at home."

\section{Institutional Factors}

\section{Strikes and Changes to Schedules}

A major challenge for learners was the interruption to course schedules and postponement of classes, particularly due to strikes. As one student reported,

"very often classes get postponed due to internal strikes and other problems in the university and [I am] unable to finish the course on time."

Changes to schedules were particularly difficult for learners when they occurred without adequate notice and when they extended the length of the programme.

\section{Lack of Contact Learning}

Many learners felt that more contact learning would help them become more successful in their programmes. This is consistent with the findings of Rajamanthri et al (2005) who reported that regular day schools was the most important factor for learner satisfaction. The learners' desire for greater contact learning may reflect their lack of understanding of ODL; however it also could be the result of inadequate course material, or difficulty contacting teachers. 


\section{Resources and Facilities}

Learners and staff also identified inadequate resources and facilities as obstacles to the successful completion of course work. Major concerns included inadequate laboratory equipment, lack of adequate library resources, computer and Internet facilities, and photocopying services. Some of the teaching and learning environments at OUSL, as well as supportive facilities, were reported to be inadequate or unprofessional (also see Rajamanthri et al., 2005). Specific concerns included:

(a) examination halls/rooms that were badly constructed and/or poorly ventilated,

(b) off-campus classrooms that are not conducive to learning or suitable for adult learners,

(c) classrooms that cannot accommodate all the learners in the class,

(d) insufficient hostel facilities,

(e) lack of facilities on campus for private study and/or group discussions, and

(f) lack of sports and recreational facilitates.

\section{Course Material}

Specific concerns regarding course material included dated material, the accuracy and originality of the content, and the aesthetic quality of the material. Indeed, Ariadurai, Abeysooriya \& Haniffa (2005) found that some of the course material provided by the OUSL have not been updated for over ten years. Both learners and teachers suggested that more audio-visual resources should be made available for learners.

\section{Lack of Contact and Communication}

Both teachers and learners voiced concerns regarding learners' inability to contact their teachers when needed. For example, one student noted,

"I come from far $(50 \mathrm{~km})$ and sometimes I have to go back home because the teacher is not there. This has happened so many times so now I do not seek much assistance from them." 
Some learners also reported that they did not receive important communications from the institution, such as registration information, course offerings, vouchers for paying tuition, changes to course schedules, examination schedules, examination results, and graduation certificates, in a timely fashion.

Polices and Practices

Learners and staff identified some policies and practices that may directly or indirectly constrain learners' abilities to succeed in their programmes, including:

(a) limited access to administrative offices and resources outside of regular office hours,

(b) complicated and time consuming administrative processes,

(c) restricted use of personal items in the library,

(d) policies that allow learners to postpone examinations for years,

(e) lack of flexibility with regard to accepting late assignments, and

(f) lack of departmental authority to enable departments to take decisions with regard to finances, as well as course offerings and programme development.

\section{Quality of Instruction}

Some learners and teachers voiced concern regarding the qualifications of some teachers. For example, one LLB student reported that he travels to Colombo to attend day schools rather than attending them in his hometown because although the teachers at his study centre are practicing lawyers, they are not effective teachers. Salaries are low for visiting lecturers and payments are often delayed. As a result it is often difficult to attract and maintain qualified teachers. Some teachers specifically requested more professional development, including instructional skills and training specific to ODL, to enhance their pedagogical practice. 
C M Hill

\section{Inadequate Support Services}

Teachers described a number of difficulties they face in fulfilling their teaching commitments, including the lack of necessary facilities, resources, and support services. As one teacher stated,

We are here to serve learners. We don't mind going for a [greater] student number, but we need basic facilities both in human resources and physical resources. Also we expect cooperation and support from the auxiliary services like press, Student affairs, exams, data processing, finance, RES and other departments who offer courses under continuing education. Then only we can ensure a consistent, quality service to our stakeholders including learners and visiting staff.

Teachers also reported that low level administrative and clerical work such as creating timetables, sending letters to learners, checking examinations, and the like, interfered with their primary duties to educate learners and conduct research. These challenges for teachers create problems for learners.

\section{Conclusions}

The findings of this study are preliminary at best; however they can provide some insight for improving learner support at the OUSL, as well as suggestions for future research. In many cases there were inconsistencies between the learners' self-assessments of their academic abilities and their reports of their actual practices, as well as teachers' beliefs regarding learners' abilities. While it is important for learners to have self-confidence in their ability to succeed academically, overestimating one's skills can have negative consequences. These include inadequate preparation, feelings of frustration, and possibly attrition. Providing a study skills course for entry-level learners may improve their understanding of ODL, provide them with a greater repertoire of study strategies, and may also increase their awareness of themselves as learners (Kruger \& Dunning, 1999).

The results of this study suggest that there are (at least) two distinct types of learners at the OUSL: PT and FT learners. As more learners are admitted to the university, the institution may be increasingly catering to FT learners. Although there is more research pertaining to the experiences of mature learners, a study conducted by Haggis and Pouget (2002) provides insight into the needs of school-leavers. The study that these learners had few effective learning strategies, and would have benefited from more explicit instructions regarding the 
nature of university education, as well as the modeling of appropriate strategies and approaches. Difficulties may arise when PT and FT learners pursue the same course credits with different amounts of time to commit to their studies. It may be beneficial for learners to receive more guidance with regard to selecting appropriate course loads, as is common in the Department of Health Sciences.

While some learners may experience personal and institutional problems that may interfere with their ability to succeed, these could be overcome because there are many established practices and innovative projects at the OUSL that enhance learner support. For example, some departments provide courses or workshops on developing academic skills. These programmes could be offered to a broader range of learners. All faculties offer student orientations, which could be coordinated and extended. The Faculty of Natural Sciences appoints a personal tutor to each new student, and the Faculty of Education has developed techniques for encouraging high quality instruction and assessment, as well as maintaining consistency at all study and regional centres. These practices could be implemented university-wide. Increasingly the library is providing digital resources, thus making them more accessible for working individuals and learners outside the Colombo area, and all faculties have made efforts to work towards providing course content online. Above all, OUSL teachers are passionate about their work with learners and committed to enhancing their pedagogical practices. The way forward is to utilize these resources, support these endeavors, and build upon these practices to maximize opportunities for academic achievement, thereby opening doors for OUSL learners.

\section{References}

Ariadurai, S. A.; Abeysooriya, B. K. P., \& Haniffa, M. R. M. (2005). A study of the factors that affect writing instructional materials for distance education learners - OUSL experiences. Extended Abstracts (pp. 110116). OUSL Silver Jubilee Academic Sessions, November 24-25, 2005. The Open University of Sri Lanka: Nawala, Nugegoda.

Biggs, J., Kember, D. \& Leung, D. Y. P. (2001). The revised two-factor study process questionnaire: R-SPQ-2F. British Journal of Educational Psychology, 71, 133-149.

Bloom, B.S., (1956). Taxonomy of educational objectives: The classification of educational goals. Handbook I: Cognitive domain. New York: Addison Wesley Publishing Company. 
C M Hill

Bereiter, C., \& Scardamalia, M. (1996). Rethinking learning. In D. R. Olson \& N. Torrance (Eds.), The handbook of education and human development: New models of learning, teaching and schooling. Cambridge, MA: Blackwell.

Calder, J. \& Wijeratne, R. (1999). The approaches to study of distance learners in two cultures: a comparative study. In R. Carr, O. J. Jegede, W. Tat-meng, \& Y. Kin-sun (eds.) The Asian distance learner. Hong Kong: Open University of Hong Kong.

Dassanayake, N., de Zoysa, S., \& Jayatilake, S. I. A. (1999). An inquiry into the factors affecting the completion of $\mathrm{M}$. Phil study programme at the Open University of Sri Lanka. The Open University of Sri Lanka: Nawala, Nugegoda.

Kruger, J, \& Dunning, D. (1999). Unskilled and unaware of it: How difficulties in recognizing one's own incompetence lead to inflated self-assessments. Journal of Personality and Social Psychology, 77, 6, 1121-1134.

Gamaathige, A. \& Dissanayake, S. (1999). A comparison of some background characteristics of students who have completed and not completed the foundations programme in social studies. OUSL Journal, 2, 65-79.

Haggis, T. \& Pouget, M. (2002). Trying to be motivated: Perspectives on learning from younger students accessing higher education. Teaching in Higher Education, 7, 3, 323-36.

Jayatilleke, B. G. (1997). Evaluation of a course in zoology: Student responses. OUSL Journal, 1, 83-102.

Jayatilleke, B. G. (2002). Asian students: are they really different? In H. P. Dikshit, S. Garg, S. Panda, \& Vijayshri (Eds.) Access and equity: challenges for open and distance learning. New Delhi: Kogan Page.

Jayatilleke, B. G. (2005). A preliminary study of the training needs for effective distance teaching and learning based on teachers' and students' perceptions of required skills. Paper presented at the SLAIHEE Conference, March 31, 2005.

Puustinen, M. \& Pulkkinen, L. (2001). Models of self-regulating learning: A review. Scandinavian Journal of Educational Research, 45, 3, 269-286.

Raheem, R., \& Ratwatte, H. V. (1997). Student profiles in English: Issues and implementation. OUSL Journal, 1, 3-27. 
Rajamanthri, S. Bulumulle, K. Goonetilleke, S., Gamini, L. P. S., Devendra, D., Vidanapathirana, U., Ranasinghe, S., \& Abeysooriya, P. (2005). An evaluation of students' perceptions of student support services (SSS) in the Faculty of Humanities and Social Sciences. Extended Abstracts (pp. 13-18). OUSL Silver Jubilee Academic Sessions, November 24-25, 2005. The Open University of Sri Lanka: Nawala, Nugegoda.

Ross, M. E., Salsbury-Glennon, J. D., Guarino, A., Reed, C. J. \& Marshall, M. (2003). Situated self-regulation: Modeling the interrelationships among instruction, assessment, learning strategies, and academic performance. Educational Research and Evaluation: an International Journal on Theory and Practice, 9, 2, 189-209.

Schunk, D. H. (2002). Self-regulation through goal setting. Eric Digest, 20024. www.ericdigersts.org/2002-4/goal.html (accessed 1 December 2005).

Simpson, O. (2002). Supporting students in online, open and distance learning. ( $2^{\text {nd }}$ edition). London: Kogan Page.

Yip, M. C. W., \& Chung, O. L. L. (2005). Relationship of study strategies and academic performance in different learning phases of higher education in Hong Kong. Educational Research and Evaluation, 11, 1, 61-70. 